\title{
Rhetorical Structure and Sociocultural Analysis of Muslim and Christian Obituaries in Jordanian Newspapers
}

https://doi.org/10.33806/ijaes2000.19.2.5

\author{
Murad Hassan Mohammed Sawalmeh \\ Dhofar University, Oman
}

\begin{abstract}
This paper gives a detailed account of the distinctive macro-structural and micro-linguistic properties used in Muslim and Christian obituaries in Jordan society. It also examines how socio-religious practices and beliefs are played out through the overall genre text. In order to examine the discourse, a move-based analysis was conducted upon a corpus of 150 Muslim obituary announcements (MOAs), and another 100 Christian obituary announcements (COAs). The analysis of textual and linguistic features is carried out by following Bhatia's (1993) model as it fruitfully illumines the relation between social discursive practice and written discourse. The genre analysis of the data demonstrates that eleven communicative moves exist in both types of obituary announcements (OAs). The study also highlights that the generic genre discourse reveals several socio-cultural and religious messages about the Jordanian community that are reflected in the rhetorical components of this genre.
\end{abstract}

Keywords: communicative moves, genre analysis, generic structure, linguistic features, obituary announcement

\section{Introduction}

Obituary announcements(OAs) can be viewed as socially conventionalized and constructed genres that belong to a set of texts referred to as "homely discourse" (Miller 1984). Homely discourse, to which OAs belong, is simply defined by Johns (1997:6) as "a recognizable socially constructed text genre of everyday language". OAs serve an incredibly important function: they announce somebody's death and provide information about funeral or memorial services. Moreover, OAs reflect, to a certain extent, the socio-economic standing of the decadent and the bereaved family, and show their academic accomplishments and professional occupations (IssaandAbuhakema2011).

Jordan is a unique model built on harmony, compassion, and mutual respect among Muslims and Christians (Abu-Taleb 2015). The spirit of understanding is regarded one of the primary elements which leads to the peaceful atmosphere flourishing in Jordan. Christians live peacefully alongside fellow Muslims. They coexist with Muslim neighbours in a special atmosphere of harmony and brotherhood and see Jordan as an exemplary model for peace, coexistence and tolerance between the two religions (Denari2014;Sawalmeh 2015; Sawalmeh 2018a). Due to this long-established relationship between Muslims and Christians, it is significant to reveal the sociocultural similarities and differences between the two religious groups as they are manifested themselves through OAs. 
An increasing body of research has primarily focused on different types of academic and professional genres (e.g. Holmes 1997; Peacock 2002; Jalilifar2010), and far little attention has been focused on how structural and linguistic features of genres such as OAs are identified and described. This study matters because, as far as the researcher is aware, no published studies appear to have investigated specifically Muslim and Christian OA genre in Jordan with the aim of identifying the key linguistic choices and border religious and sociocultural values articulated by generic sequential component organizational patterns of this genre. Therefore, this paper seeks to shine new light on the mysteries that surround this prevalent communicative event from which people can understand the rules and practices of particular social groups in a community. Learning a foreign language, as Ventola (1987: 6) put it, involves learning how to linguistically behave in cultures other than one's own. Therefore, this study offers an important opportunity for individuals who want to become familiar with the norms, values, beliefs, and practices of Muslims and Christians in Jordan.

\section{Theoretical background and review of the related literature}

A genre has traditionally been defined according to specific recurring features and communicative purposes of form and content of a text (Erickson 2000). In the 1980s, however, Miller (1984) put forward an idea that the features of form and content of discourse which typically characterize a genre should not be deemed as static conventions; rather, they should been seen as dynamic features which emerge out of the institutional and social forces which exist in the communicative situation (Freedman and Medway 1994: 8). According to Miller (1984:163), a genre text can evolve, develop or even decay. For instance, Bazerman (1988) studied how the socio-cultural changes in the context of scientific knowledge developed the discourse of the research article, and, as wedding invitations and obituary announcements are types of the developed and evolved genres through time, the diachronic perspective of such genres is important to be taken into account in this study. In the same vein, Kress and Knapp (1992) argue that while genres are considered as socially structured entities that allow for individuals' communication and reflect the continuous socioeconomic changes of communities in varied cultures, they should be themselves deemed as dynamic and apt to improve from time to time.

A genre is a typified social action since it recurrently emerges in a certain social or rhetorical setting. Therefore, an essential element in the analysis of any genre lies in understanding the social situation in which such a genre occurs. Miller's (1984) influential article Genre as a Social Action proposes that research on genre is very useful in that understanding a genre can be of great help in identifying the ways people organize, interpret and react to certain texts. She puts special focus on social aspects of discourse in her analysis of genre. Miller (1994), also, argues that a genre acquires its meaning from a given rhetorical situation and from the large social context in which this situation arose.

A genre is a communicative event which has a specific goal or purpose shared by the participants in that event. This communicative event has some constraints in 
terms of form and purpose. Thus, the emphasis is placed on the goal of the communicative event that tends to unify the individuals (Swales 1981, 1986). John Swales adds that a communicative event includes not only the discourse and its participants, but also the role of that discourse and social and cultural aspects of the environment in which the discourse is produced. He, too, declares that communicative events must share a group of communicative purposes in order to be considered as genre. Similarly, Dudley-Evans (1987) and Kress and Knapp (1992) share the same view that genre is socially defined. They describe it as a socially recognized written or spoken form that is used in social situations. It has some features of style and form that are recognized, either overtly or covertly, by individuals who use the genre. They also stress that genres are forms of texts that appear in particular social occasions characterized by members of social groups with specific social objectives, particular institutional situations and locations, as well as distinctive practices. Thus, for example, wedding invitation card and obituary announcement genres have a well-known public purpose, and have conventions about form and style that are to a large degree standardized and conventionalized.

From a social standpoint, a number of writers view genre as a cultural and social activity or practice which is based on specific discourse audience and sociocultural factors which influence discourse genres (Berkenkotter and Huckin 1993; Miller 1994; Swales and Feak 1994; Al-Ali 2005; Vergaro 2002). A genre is shaped or formed by the source's knowledge of the audience or to whom a particular genre is directed at. Its construction is highly influenced by some sociocultural factors and cultural communities (Berkenkotter and Huckin 1993; Miller 1994). Moreover, Martín and Rose (2008: 260) state that genres or genre systems play a pivotal role in shaping cultures. They also add that whether individuals consider the production of genres as being affected by socio-cultural factors or as figuring in cultural production and formation, one thing is certain; namely, the socio-cultural dimension of genre cannot be ignored. The genres investigated in this research are referred to as purposeful social activities which serve to show specific goals which express Jordanian community's way of making things happen through language. Also, in this study, I will find out how the genres of wedding invitation cards and obituary announcements are affected by such socio-cultural factors.

Any attempt to realize any genre by the texts themselves is bound to fail, as such attempts treat socially constructed categories as stable natural facts. Connor (2000: 2) confirms that a genre does not occur in isolation but should be a part of an organized or structured system of interacting genres, where each genre performs complementary social actions. Vergaro (2002) appears to support this view by claiming that comprehending a genre as a social action requires that genres be identified as such by their users. She also argues that meaning does not lie in the signs each text consists of, but it is formed by individuals by means of cognitive actions. There are, therefore, cognitive reasons that allow users speaking any language to recognize communicative events as instances of particular genres, and to assign particular terms to these events (p. 188). Therefore, in order to 
comprehend the entire purposive texts of obituary announcements which stands for a social practice, the researcher has taken into account two viewpoints, viz., identifying the texts' generic structure, which involves reference to the context of Jordanian culture, and describing linguistic and sociocultural functions related to the generic structure.

Rhetorically, OAs are classified as a genre. Bhatia (1993) defines a genre as "a recognizable communicative event characterized by a set of communicative purpose(s) identified and mutually understood by the members of the professional or academic community in which it regularly occurs." To analyze a genre, Henry and Roseberry (1999) say, a genre analyst needs to describe the move structure of the discourse and the rhetorical strategies which enable the users of the discourse to accomplish their particular communicative goal(s); the generic linguistic structures available to writers of the genre to realize these strategies; and the psychological and sociological aspects related to the textstructure, strategies and linguistic choices.

Genre theorists argue that the overall schematic structure of any genre is based on its conventional structural components, each of has its own role and typical communicative purpose, which, together with other components, contributes to the general purpose of the text(Bhatia1993). These structural components are referred to as "moves" which act as functional units of texts describing the generic structure of a genre within textual and social contexts and are applied within a certain community to achieve a specific purpose (Sawalmeh2014; Sawalmeh 2018b).

In recent years, a number of studies (e.g. Nwoye 1992; Matiki 2001; Moses and Marelli 2004; Al-Ali 2005; Aremu 2011; Ondumu 2014) have been published on obituary discourse. Nwoye (1992) investigated the general structures of 80death notices in Nigerian newspapers and compared them with English and German death announcements analyzed by Fries (1990). He pointed out that Nigerian newspapers are characterized by some obligatory elements, namely the name of the deceased person, an introduction, manner, place, and place of death, burial arrangements, survivors and some identification of the sender of the death notice. Nwoye also found that English and German OAs solely announced deaths, while Nigerian obituaries were found to be more elaborate in their information on the deadand survivors. Unlike Nwoye's study which examined the generic structure of OAs, Matiki (2001) investigated the communicative functions and pragmatic rules well govern Malawian OAs. He examined a total of 63 OAs to highlight the linguistic/sociolinguistic aspects of this genre. He identified five obligatory moves (the photograph; name of the deceased; date of death; and the addresser's name and acknowledgments), and three optional moves (the deceased's date of birth, date of funeral and use of titles). He also pointed out that Malawian OAs negotiate both the private and public domain, and are addressed to the deceased.

Moses and Marelli (2004) examined a sample of American OAs in the New York Times. They studied family authored texts and classified them as being characterized by specific obligatory moves such as the decedent's name, the date of the death, listing of family members and funeral announcements. They also 
found that these texts include an optional move (donation request) which serves to instruct members of the community on how to pay their respects. They pointed out that the kinship section is the most extensive part of the OA. Other elements are also included in the OA such as a personal history of the deceased and the circumstances of the death.

In the Arabic setting, Al-Ali (2005) identified nine rhetorical moves in two different types of OAs: normal death announcements and unusual death announcements, termed a "martyrs' weddings". He argues that these recurrent moves reflected the practices, beliefs and sociocultural norms that gave rise to these two different communicative events. He also concluded that although there were similarities in the overall communicative purpose and the generic components of these OAs, the "martyr's wedding" notices were different from normal OAs in that they promoted the dead person and communicated a feeling of honour and pride on the part of the announcer.

Aremu (2011) analyzed Nigerian obituary announcements from sociopragmatic perspective. OAs in Nigeria were found to have several linguistic properties such as lexical borrowings, metaphors, idioms, hedges, euphemisms, code-switching and code-mixing. He also found that these English OAs serve as a window through which the socio-cultural usage of Nigerian English is showcased. In a study which set out to investigate the Kenyan OAs genre in terms of the generic structure and language used, Ondimu (2014) found that the genre analysis revealed six obligatory moves in the structure of obituaries with some elements within the moves being optional. She also found that social cultural norms, attitudes and values that the Kenyan people have towards death influenced the language used in the writing of the OAs. Several attempts have been made to examine the functional moves of academic and professional discourse in Jordan. However, few writers have been able to draw on any systematic research into the generic patterns of Muslim and Christian OAs, and how Jordanian community deal with the topic of death given the values, norms and attitudes that govern the rituals of people within this society.

\section{Methodology}

\subsection{Corpus}

The OAs examined in this paper were excerpted from the funeral sections of the first-largest-circulating daily newspaper in Jordan- Al-Ra'i. Obituaries in three newspapers were scrutinized for comparison, and it was noticed that there were no substantial variations in the style or pattern of the obituaries. Prior to selecting the sample, OAs in this newspaper were examined and the researcher noticed that there were two types of death notices, viz., Muslim obituary announcements (MOAs)and Christian obituary announcements (COAs). A corpus of 250 obituary announcements (150MOAs and $100 \mathrm{COAs})$ formed the basis of this study using simple random sample design in which each OA had an equal chance of being selected to contribute to the sample. The sampled OAs were written over a period of five years, from February 2012 to July 2016. This long period, I believe, is sufficient to show any variation in the OAs. 
The selection of $A l-R a^{\prime} i$ as the source for the OAs was mainly based on two criteria. First, it is considered the most highly reputable medium to publish the largest number of Jordanian OAs, whereas other newspapers have only provided intermittent coverage. Second, it enjoys high reputation, and has the largest circulation of all domestic Arabic-language newspapers in Jordan, and thus has large readership based on its reputation. In $A l-R a^{\prime} i$, OAs usually appear in the inner side of the newspaper, and are published in a separate section entitled "announcements". They are typically seven to sixteen lines long, essentially stating the name of the decadent, and some details of the burial and funeral services.

All Jordanian OAs are paid for and submitted to the newspaper by the family of the decedent or by someone acting on the family's behalf (Al-Khatib and Salem 2011). As for the cost of the OA, it may range from $30 \$$ to $800 \$$, based on the place as well as the size of the obituary. The OA typed in large font sizes requires an extra payment, as does the use of the decedent's photo. Also, the size of the obituary announcement varies from a full-page announcement to a small one. The same obituary might be concurrently printed in different daily newspapers, and usually runs many days intermittently or consecutively. Actually, the more popular the obituary will be, the more it reveals the social status of the decedent or the family left behind (Nwoye1992; Ondimu 2014). The position, repetition and size of the OA are determined by their cost. For instance, the nearer to the first page of the newspaper the OA is displayed, the higher its cost will be. Hence, it could be argued that position, repetition and size of the OA vary based on the social statusof the decadent and his/her family members.

\subsection{Procedures}

The present study adopts both quantitative and qualitative approach, with the emphasis put on the latter. Both approaches provide insight into the nature of the death notice as a homely genre, help understand underlying reasons and motivations for its structure and content, and aim at discovering trends in the contemporary usage of the genre in question, as observed in the examined texts. Yet, the quantitative approach, though limited, is not entirely neglected, and the basic data concerning frequency and representativeness of some lexicogrammatical realizations have to be provided.

The main thrust of this paper is to identify the underlying schematic structure of MOAs and COAs. To achieve this objective, Bhatia's (1993) model of genre analysis has been adopted to find out how far this model can be generalized across other types of communication genres such as OAs. Bhatia (1993) developed Swales' framework for genre analysis and laid down a seven-step method for carrying out a comprehensive investigation of any genre, "depending upon the purpose of the analysis, the aspect of the genre that one intends to focus on, and the background knowledge one already has of the nature of the genre in question" (p. 63). Bhatia's method of genre analysis is thorough, yet flexible: while it encompasses all aspects which affect the organization of a genre, it allows a selective application of the steps. That is to say, it is unnecessary for a genre 
researcher to follow a specific order or use all the seven steps when undertaking a genre analysis. In the analysis of the genre of obituary announcements, the researcher did not follow a specific order of Bhatia's steps. Based on my research questions, the researcher mainly focused on step 6 for the examination of patterns of text textualisation and lexico-grammatical description of language use in the genres, and step 5 for the determination of the socio-cultural and religious practices and beliefs that affected the language of the genres texts. These seven steps include: (1). Placing the given genre text in a situational context, (2). Surveying existing literature, (3). Refining the situational/ contextual analysis, (4). Selecting corpus, (5). Studying the institutional context, (6). Levels of linguistic analysis (Analysis of lexical features, analysis of text-patterning or textualization, and Structural interpretation), and (7). Specialist information in genre analysis Bhatia's model was adopted because it considers a genre as a recognizable communicative event consisting of a series of moves which not only have their own purposes but also contribute to the general communicative purpose of the genre. Moreover, this model combines textual and linguistic insights with corresponding psycholinguistic and socio-cultural aspects of genre organization and interpretation. The data analysis will be predominantly based on Bhatia's (1993) notions of what main features constitute a genre. These include the discourse community that produces the genre, the communicative purpose, the structural and linguistic choices, and socio-cultural properties that appear in the overall structure of the text. In addition, I drew on Issa and Abuhakema's (2011) move structure for Egyptian obituaries to enable comparison between Jordanian obituaries and Egyptian obituaries as both of which are Islamic OAs to reveal any certain similarities and differences between the two texts.

As far as the identification of rhetorical moves are concerned, the overall communicative purposes of the genre was first identified. Then, I divided the genre into moves for the purpose of determining their communicative functions. Therefore, the moves identified in this study were assigned semantic functional values. Each move achieves has a particular purpose contributing to the overall communicative purpose of OA genre. I finally sought the help of a professor who is specialized in genre theory to determine the validity and reliability of move identification. The professor was requested to identify the moves of 50 OAs which were chosen from the sample randomly. He identified the moves and their relevant linguistic features. After that, both of us refined and reformulated all moves through engaging in several discussions until complete and clear consensus had been achieved. The inter-rater reliability regarding the identification of the moves was $90 \%$ between the researcher and the professor, which can be regarded acceptable. The analysis revealed eleven moves within the generic structure of the Jordanian OAs that will be discussed in detail in the following section.

\section{Results and discussion}

The analysis of the OAs selected from Al-Ra' $i$ newspaper has revealed that they are formed of eleven component moves which were labelled according to their 
rhetorical functions. Table 1 presents he frequency and the order of the analyzed obligatory or optional moves in both MOAs and COAs.

Table 1. Percentage of occurrences of recurrent moves in MOAs and COAs.

\begin{tabular}{llccc}
\hline No. & Type of Move & $\begin{array}{c}\text { MOAs } \\
(\mathbf{\%})\end{array}$ & $\begin{array}{c}\text { COAs } \\
(\mathbf{\%})\end{array}$ & Obligatory/Optional \\
\hline 1 & Opening & 96 & 86 & Optional \\
\hline 2 & Heading & 62 & 25 & Optional \\
\hline 3 & Announcing the death & 100 & 100 & Obligatory \\
\hline 4 & $\begin{array}{l}\text { Identifying the } \\
\text { deceased }\end{array}$ & 100 & 100 & Optional \\
\hline 5 & Photo of the deceased & 13 & 22 & Optional \\
\hline 6 & $\begin{array}{l}\text { Identifying surviving } \\
\text { relatives }\end{array}$ & 90 & 69 & Optional \\
\hline 7 & $\begin{array}{l}\text { Identifying } \\
\text { circumstances of } \\
\text { death }\end{array}$ & 86 & 75 & Obligatory \\
\hline 8 & $\begin{array}{l}\text { Funeral and burial } \\
\text { arrangements }\end{array}$ & 81 & 73 & Optional \\
\hline 9 & $\begin{array}{l}\text { Arrangements for } \\
\text { receiving condolences }\end{array}$ & 100 & 100 & Optional \\
\hline 10 & Notifications & 46 & 35 & 78 \\
\hline 11 & Closing & 83 & & \\
\hline & & & & \\
\hline
\end{tabular}

Now the individual component moves of OAs together with illustrative examples taken from the present corpus are discussed and highlighted, and the frequencies of each move are presented.

\section{Opening}

This move occurs in $96 \%$ of MOAs and $86 \%$ of COAs. In MOAs, the opening is characterized with the use of two verses taken from the Holy Quran: the formulaic verse "bismillahPalrahma:n Palrahi:m" (In the name of God, the Merciful, the Compassionate), followed by the verse "ya Payyatuha Pannafsu PalmutmaPinnahirjicai Pila: rabbikira: diyatanmardiyyahfadkhuli fi: 'aiba:diwadkhulijannati" (O (thou) soul, in (complete) rest and satisfaction! Enter thou, then, among My devotees!! Then Yea, enter thou My Heaven).

In Islam, Qur'anic verses related to obituaries perform a primary role in givingcomfort and sympathy to the decedent's family and relatives. The use of such Qur'anic verses has the purpose of encouraging the decedent's family members and relatives to accept Allah's destiny and bear patiently, which is a source of reward and blessing for them on the Day of Judgement.

Similarly, COAs use a lot of Biblical quotations such as “tu:balimanikhtartahuwaqalbuhuyarabliyaskun fi: diya:rila?a?abad" (Blessed is one whom you choose, and cause to come near, that he may live in your courts). 
These Biblical verses embody Christian people's beliefs related to death. Also, their use reveals the obituary announcer's religious background (IssaandAbuhakema2011). They are also meant to bring hope, strength, comfort, and peace to the people left behind. In general, both Muslim and Christian people seem to be religiously directed, and religion greatly influences the language used in the writing of both types of OAs since both share the same religious beliefs that surround death and the living.

\section{Heading}

This optional component move functions to basically help the obituary reader identify what the text is about, i.e., a report of death. It is written in a separate line, in bold, and with a different size font. It also occurred in $62 \%$ of MOAs and $25 \%$ of COAs.The low occurrences of this move in COAs could be accounted for by the fact that it is clearly expressed by depending on the "Opening" and "Closing" textual moves which show the use of Quranic and Biblical verses related to death, where the use of such verses reveals the purpose of the text - announcing the death of a person. In addition, the communicative function of this move is supported by the position of the OA in the newspaper (i.e., the obituary section). As for the present study, this move is optional, which contradicts Al-Ali's (2005) study. The analysis of the data indicates that this move in MOAs and COAs is communicated by using some expressions such as $n a^{\mathrm{c}} \mathrm{a} i$ (obituary), $n a^{\mathrm{c}}$ airajulfa:dilah (obituary of a virtuous man),Palbaqa:Plillah (the eternal life is only for God), etc.

\section{Announcing the death}

This move was identified in $100 \%$ of MOAs and COAs. The function of this move is to publicize the occasion of death, and present the names of the person(s)who place(s) the OA. Making public the death of the decedent, his or her family members can express their respect and emotions while inviting other people to share in their sad feeling of losing a loved one (Anderson andHan2009). Also, making known the death of the deceased could emotionally affect the OA reader and provoke an emphatic reaction (Marks and Piggee 1999).

This component move presents the person placing the OA. It usually includes a member of the deceased's tribe, a member of the official bodies related to the deceased while s/he was still alive. This result matches that observed in Al-Ali's (2005) study which indicated that the obituarist can be a member of the deceased's tribe, the whole community or some official body.

\section{Identifying the deceased}

This move is an integral part of the OA genres it appears in all MOAs and COAs. It identifies and names the departed to the readers. Usually, this move is realized by giving the full name of the dead person. It should be noted that the surname is always given in all OAs. This is perhaps to the fact that the surname reveals the importance of the tribal system in Jordan. Also, in some OAs, the deceased person's father and grandfather are not mentioned in OAs. The omission of these 
names on the part of the obituarist could be a way of saving space as words cost money when writing the OAs (Ondimu2014). OAs, which include the full name of the deceased with a bold font, belong to people having high socioeconomic statuses. This is supported by Marks and Piggee (1999) and Eid (2002) who state that the length of the OA is reflective of differences in high social statuses.

What is interesting in this move is the use of a plethora of academic and professional titles (e.g. engineer, judge, doctor, teacher, lawyer, pharmacist) before the deceased's name as the case was in Issa and Abuhakema's (2011) study. The frequent use of titles is considered an inherent feature of everyday interaction in most Arabic-speaking countries, including Jordan. This finding has also been reported in Nwoye's (1992) study which reveals that Nigerians like Jordanians love to be called by their academic, occupational or religious titles to show the social status of the deceased person and his or her family members. However, Nwoye's (1992) comparison of German and English obituaries indicated that they rarely give titles.

\section{Photo of the deceased}

This optional move, which has a non-linguistic realization, appeared in $13 \%$ of MOAs and $22 \%$ of COAs. The photo of the deceased is employed to communicatively enhance the importance of the OAs. It helps the general public identify the person who passed away. This view is supported by Matiki (2001) who stated that the photo allows people who having close relationships with the dead person to identify the deceased, given that many people can carry similar names.

Unlike Issa and Abuhakema's (2011) study in which no evidence was found for using the photo of the deceased in OAs, the findings indicated that this move is realized by the optional use of the departed person's photo. It should be noted that the use of a photo for either a man or woman is regarded a new feature in Jordanian MOAs and COAs. This finding does not support Aliakbari and Aliabadi's (2015) study on Iranian OAs which revealed that the photos of the female deceased are replaced by a bunch of flowers or a candle for religious purposes. Moreover, it is worth mentioning that not all OAs were accompanied by photos. Therefore, like Nigerian OAs (Aremu2011), and German and English OAs (Fries1990), the use of the deceased's picture in Jordanian OAs occurs less frequently; however, all Kenyan OAs (Ondimu 2014) have the photo of the deceased, which shows that the photo is an important feature of Kenyan obituaries.

\section{Identifying surviving relatives}

This move identifies close relatives who have survived the deceased such as children, wife or husband, grandchildren, siblings, nephew and niece of the decedent. This optional move was employed in $90 \%$ of MOAs and $69 \%$ of COAs. The list of the survivors in MOAs is different in length from COAs. That is to say, MOAs list the survivors in detail, while the COAs tend to list immediate family members only. This could be attributed to the fact that Muslim people have more 
survivors than Christian people. Moreover, surviving relatives might play a slightly less important role COAs than in MOAs.

It is noteworthy that Muslim and Christian people appreciate the significance of defining the decedent via his or her survivors. This practice, as Barth, Van Hoof, and Beldad (2014) put it, reveals how closely-knit family members and relatives wish to appear. The extensive use of kinship terms in both COAs and MOAs is important as it shows the strong tie between the decedent's family members, situating the obituary within the private domain (Matiki2001).

The social statuses of both the deceased and the survivors are clearly reflected in MOAs and COAsthrough mentioning their academic, professional or religious titles. All MOAs and COAs indicate the occupation of the deceased's family members and relatives, particularly if they have prestigious occupations in the society. Long (1987) states that work is an easily readable emblem of social worth, and an individual's work can locate them based on hierarchies of income, social class, authority, and prestige. The use of specific professional titles such as 'doctor', 'judge', 'pharmacist', or 'engineer', on the part of the obituarist, indicates the social status and prestige of the decedent's family members and surviving relatives.

\section{Identifying circumstances of death}

The function of this textual element is to provide the audience with clear information on the circumstances of death in terms of date, age, place, and cause. The occurrences of these variants are not all obligatory (86\% of MOAs and $75 \%$ of COAs). In more detail, the date of death is the most frequent variant written in MOAs and COAs. As for the age component, it appeared after the date of the death of the decedent. This is inconsistent with Issa and Abuhakema (2011) study on Egyptian obituaries, in which no indication of the dead person's age is shown in OAs as it is perhaps less important than the place and cause of death.

As for the place of death, the data showed that it appears to be less important than the other variants. The manner the place of death is presented is very interesting in this move. That is, the OAs have no special references to the place of death when the decedent passes away in his own country. On the contrary, when a person's death happens abroad, the place is always stated in this move. This practice often has several communicative functions. It could indicate that it is more prestigious for the obituary writer of MOAs and COAs to state that the decadent passed away, for example, in England, the USA, Spain, etc. Also, it situates the surviving family members in terms of their wealth, income, education, social mobility, etc. (Bonsu 2007; Herat 2014).

With regard to the cause of death, it is the least frequent variant and is often placed in the final position of this move. When the cause of death is mentioned, most of the instances refer to a chronic disease, a heart attack, a regrettable automobile accident, etc. It should be pointed out that making reference to the cause of death in OAs is obviously associated with the decedent's age. To illustrate, the cause of death for the dead people aged 70or over was not stated, whereas it was stated for the people under 40 of age. The practice of not stating 
the cause of death for the deceased over the age of 70 could be accounted for by the fact that the death of people at this age, according to life expectancy in Jordan, is normal. In contrast, the tendency of stating the cause of death for the decedents under the age of 40 serves crucial communicative functions. First, it arouses empathy in the OA reader, and therefore the beavered family receive heartfelt words of sympathy which help to lighten the feelings of sadness and misfortune at the loss of the loved one. Second, it could be linked to the perception that the death of a younger person is a greater shock (De Vries and Rutherford 2004). Finally, the OA writer tries to deliver a message to the reader that the death was sudden.

In this move, death is handled with special care in Muslim and Christian obituary texts to avoid bad omens as well as avoid hurting other people's feelings. Jordanian obituarists usually resort to euphemistic expressions to avoid the linguistic taboo words such as death and die with the objective of providing some sort of solace and consolation to those people left alive and help them accept the reality of the loss of a loved person. Consider the following two examples:

\section{Paladhi?intaqaliilarahmat?illah}

He who movedto the Almighty God's mercy

Paladhi?intaqaliila?al?amja:d?alsamawiyah

He who movedto the heavenly glories

In the above example, which stands for the "Identifying circumstances of death" move, it is very apparent that Muslim and Christian obituarists tend to be more euphemistic when talking about tabooed topics like death. Therefore, they resort to euphemize the term (مات ma:t) "died", which implies a sort of frightfulness and horror, by using the euphemized expression الذي انتقل الى رحمة اله "He moved to the Almighty God's mercy". Further, it is worth pointing out that the above example represents a figurative euphemism, where this euphemism implicates that the death is for the good of the deceased person, as s/he will go to the heaven. It should be mentioned that "most Arabic death terms are fatalism-laden, hence they seek to establish theistic agency and subsequently mitigate the resulting shock and grief" (Farghal 1995: 60).

\section{Funeral and burial arrangements}

This text segment specifies the arrangements about funeral and burial arrangements the relatives, friends and other people need to attend the funeral and burial ceremony. This optional move appeared with a percentage of $81 \%$ in MOAs and $73 \%$ in COAs. The readers are informed of the place (name of the church or mosque) and the time when the body is buried.

According to Islamic shariah (law), the burial should be done as soon as possible after death, which means that funeral preparations begin immediately. Muslim burial and funeral rites consist of four steps: washing the 
dead body, enshrouding it in a simple plain cotton or linen cloth, the funeral prayer and finally the burial. Likewise, Christian burial and funeral rituals start by washing the deceased person's body. After cleansing, the body is dressed and laid out at home by the family members or the funeral director. After that, the decedent is taken to the church so that the well-wishers say their last goodbyes. Then, the body of the decedent is transported to the cemetery for burial. In this context, it should be mentioned that that Jordanian Muslims and Christians share, to some extent, some rites. That is, they host a reception for the people who attended the burial and funeral, where some food and drink are offered. This could be an opportunity for the decedent's immediate family members to receive emotional support in their time of grief and give them hope during this difficult time.

\section{Arrangements for receiving condolences}

This element has valuable information on how the well-wishers can offer their condolences to the deceased person's family. In contrast to Issa and Abuhakema's (2011) study, this component is broken up into two submoves, namely, the place and the time of accepting condolences. MOAs mention two different places for men and women to express their condolences.

With regard to the time of receiving condolences, MOAs include two different timings for men and women to extend their condolences. However, COAs are characterized by referring to one specific time during which both men and women together can offer their condolences. It is worth mentioning that the traditional mourning period to honor and remember a decedent is three days for both Muslims and Christians, where family and friends often pay condolence visits during this period of mourning.

There are also some variations in linguistic choices that occur between MOAs and COAs.Muslims, for example, use the expression "tuqbalaltacaa:zi fi: [place and time]" (Condolences will be accepted at [place and time], to inform the obituary readers about the arrangements for accepting condolences. However, the expression "yoqa:mu?alquda:s?alPila:hi fi:[place and time]" (the mass will be received at [place and time]" is used by Christians for the same communicative purpose.

\section{Notifications}

This rhetorical move includes extra information for people who want to offer their condolences. Although the low occurrence of this move (46\% in MOAs and 35\% in COAs), it appears to be very significant in terms of providing the obituary reader with further information about expressing condolences. The move contains some notices such as the email address, mobile phone numbers, the family of the deceased's fax number so that the colleagues and friends of the decedent get the opportunity to engage in this sad occasion and convey their heartfelt condolences. In addition, the special mention of such notices in the obituary would allow the decadent's friends or relatives living abroad to send their sincere condolences via phone calls, emails, telegraphs, and so forth. 


\section{Closing}

This move, which occurred in $83 \%$ of MOAs, and $78 \%$ COAs, has an important purpose, namely closing OAs courteously and politely. In MOAs, the realization of the "Closing" move was achieved by using different rhetorical expressions: a Quranic verse, invocation, and asking the obituary reader to recite Al-fatiha(the first surah (chapter) of the Quran). The following are some prevalent examples written as closing expressions: "nas?alukum?alfatiha" (We ask you for AlFatiha); and"Pina: lila:hwaPina: Pilaihira:jicau:n" (Indeed we belong to Allah, and indeed to Him we will return).

As for COAs, various rhetorical Biblical expressions are also employed to close the obituary. Here are some examples: "walyakundhikra:humuabadan" (May he remembered for eternity); "Palmasi:hqa:mahaqanqa:ma" (Christ has truly risen).

\section{Conclusion}

This study has set out to examine the MOAs and COAspublished in Al-Ra' $i$ newspaper. It has been mainly concerned with identifying the macro-rhetorical moves, and the peculiar micro-linguistic realizations of the discoursal units under the impact of the socio-religious forces encoded in the discourse of this communicative event.

More specifically, the analysis of the MOAs and COAs, which has been conducted based on the notion of move-based approach and the socio-religious practices and values that put constraints on the overall generic structure of the texts, has revealed that they are composed of eleven rhetorical moves. Every move has a specific communicative function of their own which contributes, in some way, to fulfilling the overall purpose of that particular genre (Bhatia 1993; Bonyadi 2010). The overall organizational discourse of MOAs and COAswas found to be substantially structured and conventionalized in terms of semantic values, content, and form; however, the rhetorical moves did not appear in a totally fixed structure, but some slight differences existed in move order and frequency.

Most aspects of Jordanian people's life, including death have been affected by religious beliefs. Thus, it is not surprising to find out that the textual and linguistic structure reflected in various moves of MOAs and COAs exhibit several properties of the major influences exercised by religious practices and beliefs of Muslim and Christian people. Therefore, the results of the investigation have indicated that MOAs and COAsare set in a frame of religious language which performs an important role in revealing and shaping the obituary writer's socio-religious identity. For example, the different religious affiliations of the decedents and their family members reflected in the form of Qur'anic and Biblical verses used in the genre texts or other religious traditions manifested themselves in in the way the texts were interpreted and constructed. In addition, the study showed that the language of MOAs and COAswas fraught with religious lexical choices reflecting the religious values and beliefs of the genre producer. 
In addition, the present study has shown that the sociocultural atmospheres are presented in the formulaic structure of MOAs and COAs. For instance, one of the sociocultural practices which was evident in the corpus is the heavy use of professional and academic titles in two moves, namely, "Identifying surviving relatives" and "Identifying the deceased". The frequent reference to the titles, which are typed in bold-face with varied font sizes, fosters social values and show that Muslim and Christian people belong to high socio-economic status in their society.

The use of euphemistic words or phrases was also evident in MOAs and COAs. For instance, it has been noticed that the unpleasant and excruciating verb (ma:t) "died" is obviously avoided by obituary writers when making reference to death directly. instead, they speak of it euphemistically by replacing it by more felicitous soft boiled and less harmful expressions such as "PaladhiPintaqalPilarahmat?illah" (He moved to the Almighty God's mercy). This expression was used by Muslim and Christian people as they have a strongly-held belief that death is not the end to our existence; rather, it is a passage, which takes us from the earthly life to the hereafter. Therefore, they presuppose that the decedent has been granted mercy to go to paradise.

While the present study presents an extensive investigation of the generic structure of MOAs and COAs, it does not examine gender-related differences between Muslim and Christian people reflected in the organizational structure and lexical choices of the genre text. Also, the present study focuses on the examination of written OAs only. Therefore, future studies done on electronic and spoken OAs in Jordanian society would be of deep significance in showing any similarities and differences related to linguistic realization patterns and generic conventions of the texts that would develop a more thorough understanding of such genres. Moreover, this study still requires future comparative cross-cultural and intracultural research. It would be worthwhile, for example, to compare Jordanian OAs with the American or British ones to reveal if there are crosscultural similarities and differences in their textual and linguistic realizations. Finally, this study also analyses samples over a four-year period in one newspaper. Studying OAs over a longer period of time in various newspapers might reveal the appearance of different discoursal components and explore how these genres might be evolved over time in terms of formality, design, text length, colour, size, typography, among many others.

Murad Sawalmeh

Department of English Language and Literature

Dhofar University

Oman

msawalmeh@du.edu.om 


\section{References}

Abu Taleb, Salem.(2015). Religion and faith.

http://www.myjordanjourney.com/religion-and-faith/(Retrieved on 7 March, 2016).

Al-Ali, Mohammed. (2005). 'Communicating messages of solidarity, promotion and pride in death announcements genre in Jordanian newspapers'. Discourse and Society, 16 (1): 5-31.

Aliakbari, Mohammad and Hassan Tarlani-Aliabadi. (2016). 'Communicating sociocultural norms and social and religious practices in Iranian death notices'. Social Semiotics, 26 (2):185-207.

Al-Khatib, Mahmoud Abed, and Zainab Salem. (2011). 'Obituary announcements in Jordanian and British newspapers: A cross-cultural overview'. ActaLinguistica, 5 (2):80-96

Aremu, Moses Adebayo. (2011). 'A social pragmatic analysis of obituary announcements in English in Nigeria'. Journal of the Nigeria English Studies Association, 14 (2):132-143.

Ask, Karin and MaritTjomsland. (1998). Women and Islamization: Contemporary Dimensions of Discourse on Gender Relations. Bloomsbury Academic.

Barth, Susanne, Joris J. Van Hoof and Ardion D. Beldad. (2014). 'Reading between the lines: A comparison of 480 German and Dutch obituaries'. OMEGA-Journal of Death and Dying, 68 (2):161-181.

Bazerman, Charles. (1988). Activity of the Experimental Article in Science. Madison: University of Wisconsin Press.

Berkenkotter,Carol and Thomas Huckin. (1993). 'Rethinking genre from a sociocognitive perspective'. Written Communication, 10 (4): 475-509.

Bhatia, Vijay. (1993). Analyzing Genre: Language Use in Professional Settings. London: Routledge.

Bonyadi, Alireza. (2010). 'The rhetorical properties of the schematic structures of newspaper editorials: A comparative study of English and Persian editorials'. Discourse and Communication, 4 (4):323-342.

Bonsu, Samuel K. (2007). 'The presentation of dead selves in everyday life: Obituaries and impression management'. Symbolic Interaction, 30 (2):199219.

Connor, Ulla. (2000). Variation in rhetorical moves in grant proposals of US humanists and scientists. Text-Interdisciplinary Journal for the Study of Discourse, 20 (1): 1-28.

Denari, Jordan. (2014). Pope Francis' Holy Land Visit: Spotlight on Christians in Jordan. http://time.com/110595/pope-francis-holy-land-visitspotlight-on-

christians-in-jordan/ (Retrieved on March 27, 2016)

De Vries, Brian and Judy Rutherford. (2004). 'Memorializing loved ones on the World Wide Web'. OMEGA-Journal of Death and Dying, 49 (1):5-26. 
Dudley-Evans, Tony. (1987). 'Introduction to Genre Analysis and ESP'. ELR Journal, 1:27-39.

Eid, Mushira. (2002). The World of Obituaries: Gender Across Cultures and Over Time. Detroit: Wayne State University Press.

Erickson, Thomas. (2000). Making sense of computer-mediated communication (CMC): Conversations as genres, CMC systems as genre ecologies. In System Sciences, 2000. Proceedings of the 33rd Annual Hawaii International Conference on IEEE.

Farghal, Mohammed. (2005). 'Arabic euphemism in English translation'. International Journal of Arabic-English Studies, 6:57-71.

Fries, Udo. (1990). A Contrastive Analysis of German and English Death Notices. Philadelphia: Benjamins Publ.

Henry, Alex and Robert L. Roseberry. (1999). 'Raising awareness of the generic structure and linguistic features of essay introductions'. Language Awareness, 8 (3):190-200.

Herat, Manel. (2014). 'Avoiding the reaper: Notions of death in Sri Lankan obituaries'. International Journal of Language Studies, 8 (3):117-144.

Holmes, Richard. (1997). 'Genre analysis, and the social sciences: An investigation of the structure of research article discussion sections in three disciplines'. English for Specific Purposes, 16 (4):321-337.

Issa, Sadam and Ghazi Abuhakema. (2012). 'Rhetorical Properties and Generic Structure Analysis of Christian and Muslim Obituaries'. Al-'Arabiyya, 45 (11): 44-65.

Jalilifar, Ali Reza. (2012). 'Research article introductions: Sub-disciplinary variations in Applied Linguistics'. Journal of Teaching Language Skill, 29 (2): 29-55.

Johns, Ann. (1997). Text, Role and Context: Developing Academic Literacies. Cambridge: Cambridge University Press.

Kress, Gunther and Peter Knapp. (1992). Genre in a social theory of language. English in Education, 26 (2): 4-15.

Long, Gary L. (1987). 'Organizations and identity: Obituaries 1856-1972'. Social Forces, 65 (4): 964-1001.

Marks, Alan and Tommy Piggee. (1999). 'Obituary analysis and describing a life lived: The impact of race, gender, age, and economic status'. OMEGAJournal of Death and Dying, 38 (1): 37-57.

Martin, James and David Rose. (2008). Genre relations: Mapping culture. London: Equinox Pub.

Matiki, Alfred. (2001). 'The pragmatics of obituary notices in Malawian newspapers'. Language Matters: Studies in the Languages of Southern Africa, 32 (1):29-52.

Miller, Carolyn R. (1984). 'Genre as social action'. Quarterly Journal of Speech, 70 (2): 151-167.

Miller, Carolyn. (1994). 'Rhetorical community: The cultural basis of genre'. Genre and the New Rhetoric, 55 (4): 67-78. 
Moses, Rae A. and Giana D. Marelli. (2003). 'Obituaries and the discursive construction of dying and living'. Proceedings of the Eleventh Annual Symposium about Language and Society, Austin.

Nwoye, Onuigbo G. (1992). 'Obituary announcements as communicative events in Nigerian English'. World Englishes, 11(1):15-27.

Ondimu, Jacquiline. (2014). 'A socio-cultural understanding of death: A genre analysis of obituaries in a Kenyan newspaper'. Language Matters, 45(1):322.

Peacock, Matthew. (2002). 'Communicative moves in the discussion section of research articles'. System, 30 (4):479-497.

Sawalmeh, Murad Hassan Mohammed. (2014). 'A sociolinguistic study of Muslim and Christian wedding invitation genre in the Jordanian society'. Journal of Advances in Linguistics, 5 (1):448-462.

Sawalmeh, Murad Hassan Mohammed. (2015). Ceremonial Arabic writing: A genre-based investigation of wedding invitation cards and obituary announcements in Jordanian society. Unpublished $\mathrm{PhD}$ Thesis, University of Huddersfield, Hudderfield, UK.

Sawalmeh, Murad Hassan Mohammed. (2018a). 'Death notices as communicative events: An analysis of linguistic features in Jordanian newspapers'. International Journal of Humanities and Social Development Research, 2 (2):79-93.

Sawalmeh, Murad Hassan Mohammed. (2018b). 'Jordanian wedding invitation as a genre: An analysis of rhetorical structure and linguistic features'. International Journal of Linguistics, Literature and Translation, 1 (1):106127.

Swales, John. (1981). Aspects of Article Introductions: Language Studies Unit, University of Aston in Birmingham.

Swales, John. (1986). Citation analysis and discourse analysis. Applied Linguistics, 7(1), 39-55.

Swales, John and Christine Feak. (1994). Academic Writing for Graduate Students: Essential Tasks and Skills. Ann Arbor, MI: The University of Michigan Press.

Ventola, Eija. (1987). The Structure of Social Interaction: A Systemic Approach to the Semiotics of Service Encounters. London: Pinter Pub Ltd.

Vergaro, Carla. (2002). 'Dear Sirs, what would you do if you were in our position? Discourse strategies in Italian and English money chasing letters'. Journal of Pragmatics, 34 (9): 1211-1233. 